\title{
An Approach to the Influence of Particle Size Distribution of Leuco Vat Dye Converted by a Reducing Agent
}

\author{
Woo Sub Shim*, Jung Jin Lee ${ }^{1}$, and Renzo Shamey \\ Fiber and Polymer Science Program, North Carolina State University, Raleigh, NC 27695-8301, USA \\ ${ }^{1}$ Department of Textile Engineering, Dankook University, Seoul 140-714, Korea \\ (Received January 25, 2006; Revised March 23, 2006; Accepted April 2, 2006)
}

\begin{abstract}
Three vat dyes have been applied to regular viscose rayon and their dyeing and wash fastness properties were evaluated. Particle size determination was undertaken to obtain information about the size of dye particles converted by a reducing agent, to see if dye particle size has an affect on dyeing properties of regular viscose rayon. It is observed that viscose rayon exhibits more dyeability with reducing agent concentrations between 5-7.5 g/l. Also, we found that the vat dyeing system is greatly affected by the particle size of the vat dye converted to leuco form by a reducing agent.
\end{abstract}

Keywords: Particle size, Particle size distribution, Reducing agent, Viscose rayon, Vat dye, Dyeing properties, Wash fastness

\section{Introduction}

Vat dyes are used to dye cellulosic fibers in relatively dull shades requiring good fastness. They are insoluble in water and cannot be used directly for dyeing cellulosic fibers. In the vatting process, vat dyes are reduced in an alkaline medium and converted to the soluble leuco form, which has substantivity to cellulosic fibers. The soluble leuco form penetrates into the fibers. The original insoluble structure is restored upon subsequent oxidation and the dye is retained within the fibers [1,2]. Vat dyes usually have outstanding color fastness properties compared to other dyes.

Reducing agents are compounds which either donates hydrogen to, subtract oxygen from or add electrons (negative charge) to other chemicals. The affected chemicals are said to be reduced. During the reduction process, the reducing agent itself is changed (oxidized), often irreversibly. For example, vat dye structure in Figure 1(b) the soluble sodium leuco vat, or Figure 1(c) the sparingly soluble leuco vat-acid, which have an added negative charge and a hydrogen atom respectively. In vat dyeing, the reducing agent of choice, sodium hydrosulfite, commonly known as hydro, but more correctly known as sodium dithionite, has the chemical formula $\mathrm{Na}_{2} \mathrm{~S}_{2} \mathrm{O}_{4}$. This compound is not stable in neutral or acidic solutions but is stable in strongly alkaline solutions in the absence of air. The vatting process consists of reduction of keto groups on the dye structure using sodium hydrosulfite

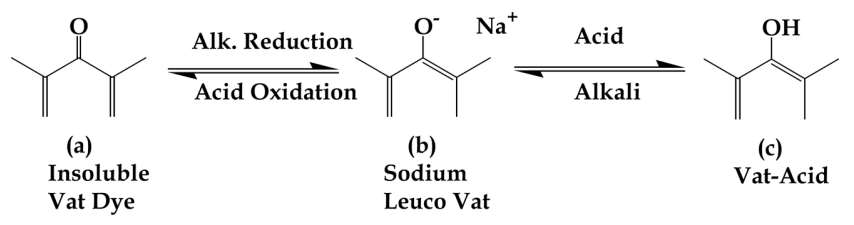

Figure 1. Vat dye functional groups and their dyeing reactions.
$\left(\mathrm{Na}_{2} \mathrm{~S}_{2} \mathrm{O}_{4}\right)$. The name "hydro" is commonly used for sodium hydrosulfite in the dyehouse. Reduction is done in the presence of sodium hydroxide $(\mathrm{NaOH})$ which is usually called caustic. The quantities of caustic and hydro required depend on how many keto groups in the dye molecules are reduced. One mole of hydro is required to reduce two keto groups to the enol form. Theoretically, one mole of caustic is required to convert each enol group to its salt form Figure 2. To be practically useful, solutions of a vat dye reducing agent must have a level of reducing power (or reducing potential) sufficient to reduce all commercial vat dyes to their water soluble forms, economically and quickly, without converting the dyes to products from which the original pigments cannot be restored (over reduction) [3].

The commonly used measurements of particle sizes are the length (the longest dimension from edge to edge of a particle oriented parallel to the ocular scale) and the width (the longest dimension of the particle measured at right angles to the length). One of the most widely used derived descriptors is the projected area diameter, which is the diameter of a circle having the same area as the projected area of the particle resting in a stable position [4]. The concept of projected area diameter is illustrated in Figure 3.

In this study, three vat dyes were applied to regular viscose rayon, and their dyeing properties were investigated by measuring the particle size under different conditions during the vatting process. Wash fastness of the dyed viscose rayon was also evaluated.

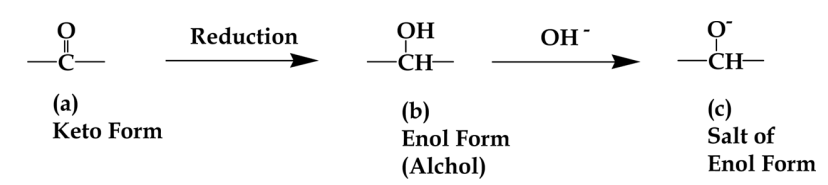

Figure 2. Keto and enol form by reduction.

*Corresponding author: jacob0720@gmail.com 


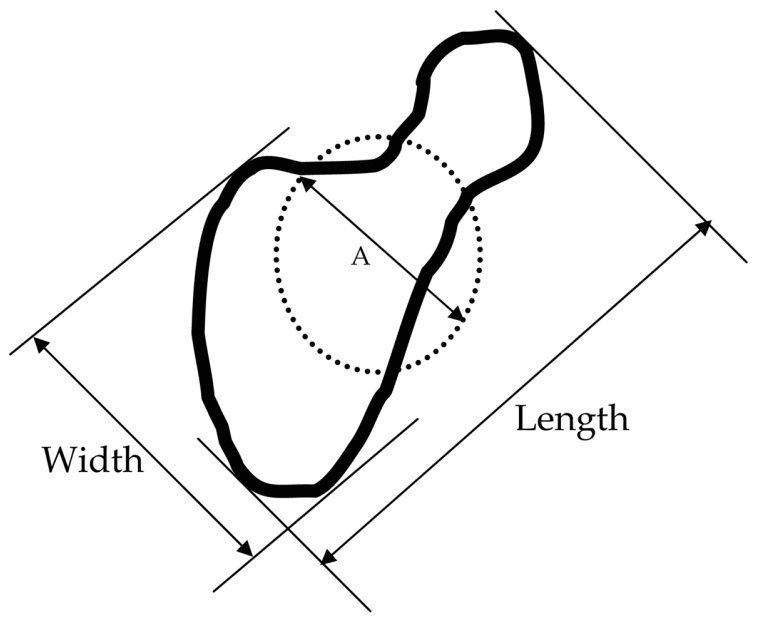

A: Projected area diameter

Figure 3. A commonly used descriptions of particle size.

\section{Experemental}

\section{Materials}

The scoured, woven fabrics of viscose rayon (plain weave, warp 82 threads/inch, weft 62 threads/inch and filament fineness 2.5 denier/filament) was procured from SK Chemicals Co., Ltd., South Korea. The three vat dyes employed, Indanthren Blue BC (C.I. Vat Blue 6, BASF), Indanthren Brilliant Pink R (C.I. Vat Red 1, BASF), Cibanone Green (C.I. Vat Green 1, Ciba Specialty Chemicals Co.) and their structures are shown in Figure 4. They were used as such without any purification prior to use. Peregal $\mathrm{P}(0-2 \mathrm{~m} / / \mathrm{l})$, used as a leveling agent, was supplied by BASF. Setamol WS, a dispersing agent, and Dekol SN, a soaping agent, were supplied by Dae-Yang TexChem Co. Sodium hydrosulfite $\mathrm{Na}_{2} \mathrm{~S}_{2} \mathrm{O}_{4}, 0$ $20 \mathrm{~g} / l$ ), used as a reducing agent and sodium hydroxide $(\mathrm{NaOH})$ were purchased from Sigma Aldrich Chemicals Co. All the other chemicals used were of laboratory grade.

\section{Dyeing Process}

The rayon fabric was dyed in an IR dyeing machine (DL6000A, Dae-Lim Co., Ltd., Korea) using the dyeing profile shown in Figure 5. Dyeing was commenced at $30{ }^{\circ} \mathrm{C}$. The dyebath temperature was raised $1{ }^{\circ} \mathrm{C} / \mathrm{min}$ to $60{ }^{\circ} \mathrm{C}$. The temperature was maintained at each temperature for 30 minutes, and then rapidly cooled to room temperature. At the end of the dyeing process, the dyed fabrics were removed and rinsed thoroughly in cold water. Oxidation was carried out with $2 \mathrm{ml} / \mathrm{l}$ hydrogen peroxide solution $(30 \% \mathrm{w} / \mathrm{v})$ for $15 \mathrm{~min}$ at $60{ }^{\circ} \mathrm{C}$. Finally, the dyeings were soaped in an aqueous solution of $2.5 \mathrm{~g} / \mathrm{l}$ Dekol SN for $15 \mathrm{~min}$ at a boil.

\section{Measurement of Particle Size of Vat Dye}

To measure particle size, we employed the Zetasizer 3000<smiles>O=c1c2ccccc2c(=O)c2c1ccc1[nH]c3c(=O)c4ccccc4c(=O)c3c(Cl)cc12</smiles>

C.I. Vat Blue 6 (C.I. 69825)<smiles>Cc1cc(Cl)cc2c1S/C(=C1/Sc3cc(Cl)cc(C)c3C1=O)C2=O</smiles>

C.I. Vat Red 1 (C.I. 73360$)$

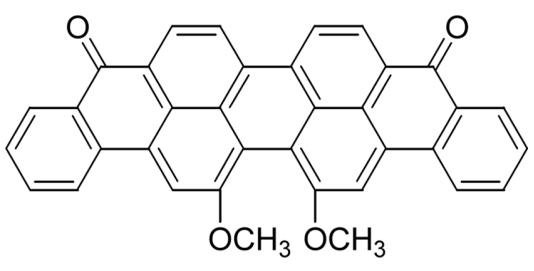

C.I. Vat Green 1 (C.I. 59825)

Figure 4. Structure of dyes used in this study.

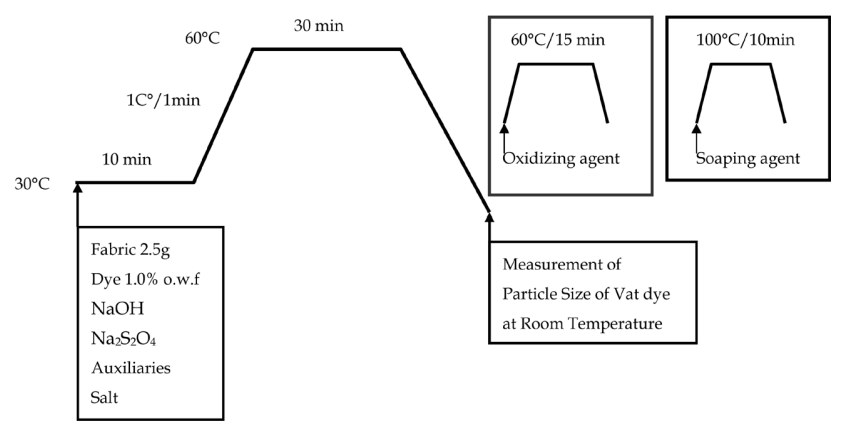

Figure 5. Vat dyeing profile on viscose rayon.

HSa (Malvern instruments Ltd., United Kingdom). We measured the particle size of leuco vat dye while varying the amount of reducing agent, to determine the effect on the vat dyeing process.

The arithmetic mean of the ensemble of particle diameters is calculated using the relation,

$$
d_{a v}=\frac{\sum n d_{i}}{\sum n}
$$


Where, $n$ is the number of particles having a diameter equal to $d_{i}$.

The standard deviation in the distribution then is calculated using

$$
\sigma_{d}^{2}=\frac{\sum\left(d_{a v}-d_{i}\right)^{2}}{\sum n}
$$

\section{Measurement of Color Yield}

The color yield of the dyed fabric was determined from the $\mathrm{K} / \mathrm{S}$ values by measuring the reflectance at the wavelength of maximum dye absorption using a Macbeth Coloreye 3000 Spectrophotometer (Illuminant D65, $10^{\circ}$ observer).

$$
K / S=\frac{(1-R)^{2}}{2 R}
$$

Where, $R$ : the reflectance of an infinitely thick layer of the material illuminated with light of a known wavelength

$K$ : the absorption coefficient

$S$ : the scattering coefficient

\section{Assessment of Wash Fastness}

The viscose rayon was dyed to give a $1 / 1$ standard depth. The dyed fabric was heat-set at $170{ }^{\circ} \mathrm{C}$ for 60 seconds and tested for fastness to washing (ISO $105 \mathrm{C} 06 / \mathrm{C} 2 \mathrm{~S}$ ). The shade change, together with the staining of adjacent fabrics, was assessed using Grey Scales.

\section{Results and Discussion}

During dyeing, the dye molecule has to enter the intercellular spaces of the fiber in which it has to be fixed. If we take the swelling of the viscose rayon during the wet treatment into consideration, the diameter of the fiber channels varies between $20 \AA\left(1 \AA=10^{-1} \mathrm{~nm}\right)$ and $40 \AA$ [5]. The particle size of leuco vat dye converted by reducing agent influenced the time of reduction required to establish the vat dyeing process. A decrease in the particle size thus shortens the time required for dyeing in equilibration. Large particles would mitigate high resistance to enter the fiber.

Table 1 shows the variation in amount of reducing agent and their effect on particle size, the average particle size, and standard deviation at max number frequency of three vat dyes. The molecules of vat dyes converted by reducing agent are smaller than those without reduction. As the amount of reducing agent is increased in the vatting process, the particle sizes of the vat dyes were decreased. Much smaller molecules of vat dyes may be suitable for dyeing the fabric because the leuco vat dye can easily penetrate and fix on viscose rayon. A smaller particle size of vat dyes could provide an improved dispersion. Thus, because the reduction in particle size of vat dye could enhance dispersibility in the vat dyeing process, there was an increase in the color strength of dyeings. However,
Table 1. Effect of amount of reducing agent $\left(\mathrm{Na}_{2} \mathrm{~S}_{2} \mathrm{O}_{4}\right)$ on range of particle size $(\mathrm{nm})$, average particle size and standard deviation at max number frequency with three vat dyes using Zetasizer $3000 \mathrm{HSa}$

\begin{tabular}{ccccc}
\hline Dye & $\begin{array}{c}\text { Reducing } \\
\text { agent } \\
\left(\mathrm{Na}_{2} \mathrm{~S}_{2} \mathrm{O}_{4},\right. \\
\mathrm{g} / l)\end{array}$ & $\begin{array}{c}\text { Range of } \\
\text { particle } \\
\text { size } \\
(\mathrm{nm})\end{array}$ & $\begin{array}{c}\text { Average } \\
\text { particle size } \\
\text { at max number } \\
\text { freguency } \\
\left(d_{a v}\right)\end{array}$ & $\begin{array}{c}\text { Standard devia- } \\
\text { tion of average } \\
\text { at max number } \\
\text { frequency } \\
\left(\sigma_{d}\right)\end{array}$ \\
\hline C.I. Vat & 5 & $62.9 \sim 408.8$ & 115.6 & 4.2 \\
Blue 6 & 7.5 & $19.3 \sim 192.8$ & 45.3 & 1.7 \\
& 15 & $13.3 \sim 34.6$ & 41.7 & 1.5 \\
& 20 & $10.2 \sim 28.2$ & 20.9 & 0.8 \\
\hline & 0 & $56.1 \sim 446.5$ & 309.1 & 0.76 \\
C.I. Vat & 5 & $31.1 \sim 155.7$ & 53.4 & 11.2 \\
Red 1 & 7.5 & $14.3 \sim 71.9$ & 21.3 & 1.9 \\
& 15 & $13.2 \sim 40$ & 17.6 & 0.8 \\
& 20 & $12.6 \sim 28$ & 16.9 & 0.7 \\
\hline & 0 & $72.5 \sim 458$ & 331.7 & 0.6 \\
C.I. Vat & 5 & $31.4 \sim 155.9$ & 34.9 & 12.1 \\
Green 1 & 7.5 & $27.7 \sim 137.6$ & 31.2 & 1.3 \\
& 15 & $18 \sim 124.6$ & 28.4 & 1.1 \\
& 20 & $15.2 \sim 87.4$ & 24.1 & 0.8 \\
\hline
\end{tabular}

excessive hydro has a negative effect on dyed fabrics. With increasing concentration of hydro in the dyeing process, the dyed fabric could not produce high color yield. This is because the hydro is dissolving the leuco vat dye which can represent the color.

Figures 6-8 shows the effect of varying the amount of reducing agent on number frequency of vat dyes on viscose rayon. According to increasing concentration of reducing agent, particle sizes of leuco vat dyes converted by the reducing agent were more and more decreased. Especially, there were maximums of number frequency of leuco vat dyes at different amounts of reducing agent. The max number of frequency of C.I. Vat Blue 6, Red 1 and Green 1 were 5-7.5 g/l of reducing agent. Also, we found that the vat dye if not converted to leuco form using reducing agent, the fabric could not be dyed. Particle size distributions can be sorted according to the volume of the particles contained within a given size band or to the number of particles contained in the same size band. All analyst know that the particles in solution that constitute real samples of substances do not consist of any single type, but instead will generally exhibit a range of shapes and sizes. Particle size determinations therefore are undertaken to obtain information about the size characteristics of an ensemble of particles. Furthermore, because the particles being studied are not the exact same size, information is required about the average particle size and the distribution of sizes about that average [6]. Similar results were obtained 


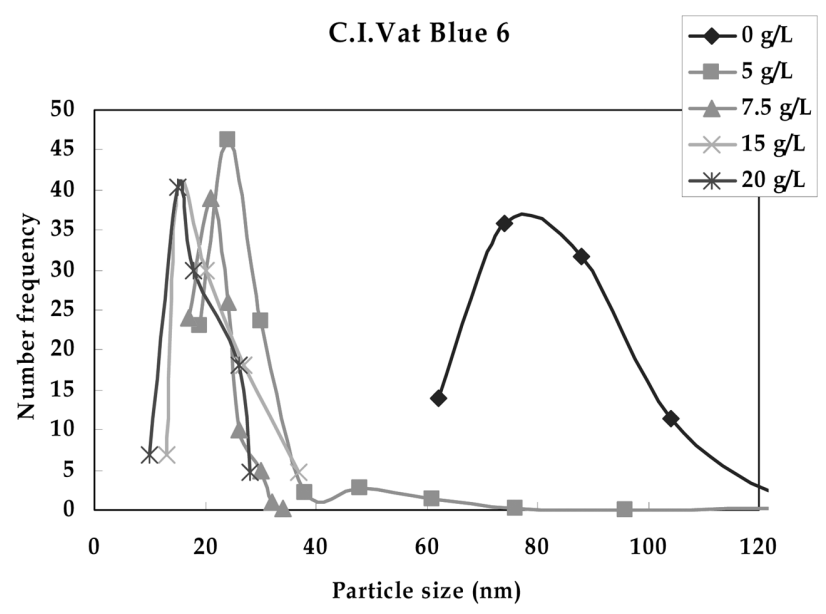

Figure 6. Effect of amount of reducing agent $\left(\mathrm{Na}_{2} \mathrm{~S}_{2} \mathrm{O}_{4}\right)$ on number frequency of C.I. Vat Blue 6 on viscose rayon; for key Figure 5.

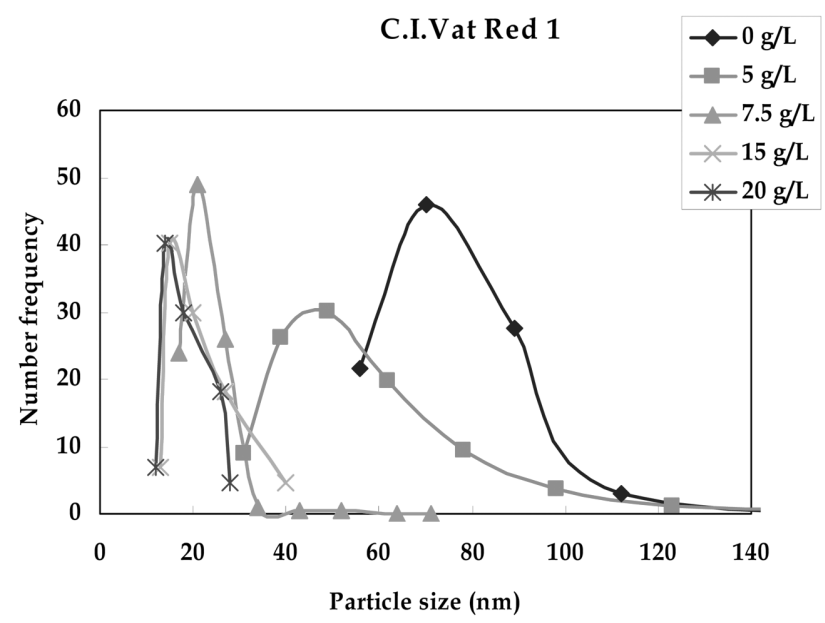

Figure 7. Effect of amount of reducing agent $\left(\mathrm{Na}_{2} \mathrm{~S}_{2} \mathrm{O}_{4}\right)$ on number frequency of C.I. Vat Red 1 on viscose rayon; for key Figure 5.

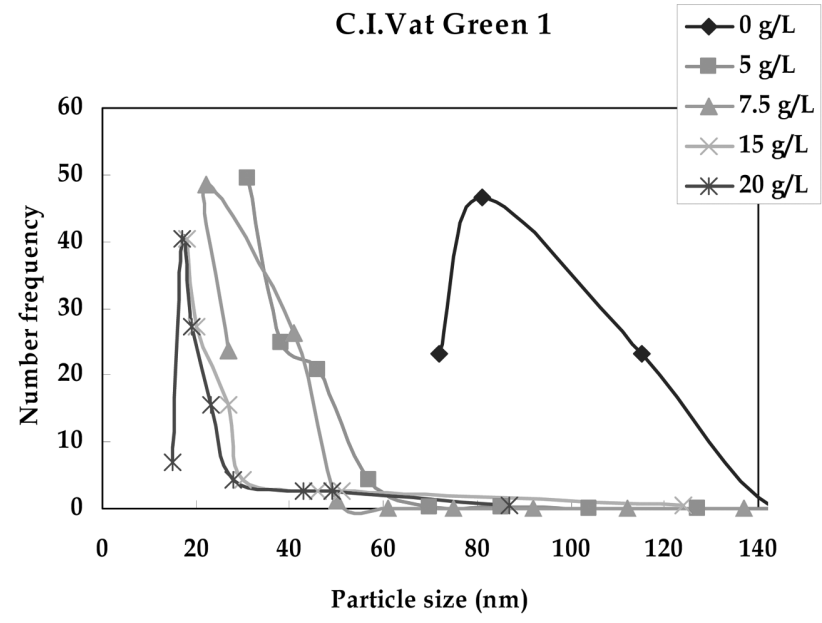

Figure 8. Effect of amount of reducing agent $\left(\mathrm{Na}_{2} \mathrm{~S}_{2} \mathrm{O}_{4}\right)$ on number frequency of C.I. Vat Green 1 on viscose rayon; for key Figure 5.

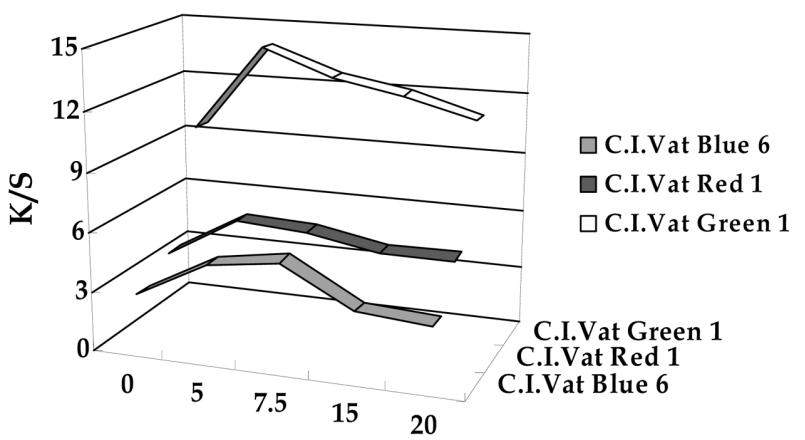

Reducing agent $(\mathrm{g} / \mathrm{L})$

Figure 9. Effect of amount of reducing agent $\left(\mathrm{Na}_{2} \mathrm{~S}_{2} \mathrm{O}_{4}\right)$ on color yield $(\mathrm{K} / \mathrm{S})$ of vat dyes on viscose rayon; for key Figure 5.

for C.I. Vat Red 1 and Blue 6.

Figure 9 shows the effect of the amount of reducing agent on color yield of vat dyes on viscose rayon. A decrease in the particle size shortens the time required for dyeing in equilibration. Larger molecules have a harder time diffusing into the fiber and take more time. Decreased particle sizes exhibited good color yield on the fabric and the color strength rose when reducing agent added was between 5$7.5 \mathrm{~g} / l$. However, when we added reducing agent over $10 \mathrm{~g} / l$ to the dye solution, dye molecules were converted to very small particles by over reduction. The dye molecule lost its ability to dye rayon when adding excessive reducing agent even though the decreased particle size of the lecuco vat dye is easier to penetrate fibers. Also, when we added no reducing agent to the dye solution, dye molecules were not converted to the leuco form. Thus, dye molecules could not fix to make color in the fiber but automatically just penetrate without fixing in the internal region. Similar data was obtained for C.I. Vat Red 1 and Blue 6.

Table 2 shows that the fastness to washing of $1 / 1$ standard depth dyeing of three vat dyes on viscose rayon is slightly higher when the reducing agent concentration is between 5$7.5 \mathrm{~g} / l$. The results of the wash fastness test for three vat dyes on viscose rayon are summarized in Table 2. In exchange for their cost, vat dyes can deliver dyeing with arguably the highest levels of washing and wet fastness properties. Vat dyeing has several good properties which make them very difficult to overlook for dyeing some industrial yarns, terry cloth, industrial work clothing and shirting fabrics [7,8]. All dyes showed good to excellent wash fastness on viscose rayon with reducing agent $(5-7.5 \mathrm{~g} / l)$. While we varied the reducing agent from $0-15 \mathrm{~g} / l$ and over $15 \mathrm{~g} / l$, we found some staining on acetate and nylon. This result can be attributed to the insolubility of the vat dye characteristics.

\section{Conclusions}

We investigated the dyeing and fastness properties of regular 
Table 2. The wash fastness of the vat dyes on viscose rayon

\begin{tabular}{|c|c|c|c|c|c|c|c|c|}
\hline \multirow{2}{*}{ Dye } & \multirow{2}{*}{$\begin{array}{c}\text { Reducing agent } \\
\left(\mathrm{Na}_{2} \mathrm{~S}_{2} \mathrm{O}_{4}, \mathrm{~g} / l\right)\end{array}$} & \multirow{2}{*}{ Change } & \multicolumn{6}{|c|}{ Staining } \\
\hline & & & Acetate & Cotton & Nylon & Polyester & Acrylic & Wool \\
\hline \multirow{5}{*}{$\begin{array}{c}\text { C.I. } \\
\text { Vat Blue } 6\end{array}$} & 0 & $3 / 4$ & 4 & 5 & $3 / 4$ & 5 & 5 & 5 \\
\hline & 5 & $4 / 5$ & 5 & 5 & 4 & 5 & 5 & 5 \\
\hline & 7.5 & $4 / 5$ & 5 & 5 & 5 & 5 & 5 & 5 \\
\hline & 15 & 4 & 5 & 5 & 5 & 5 & 5 & 5 \\
\hline & 20 & 3 & 4 & 5 & 5 & 5 & 5 & 5 \\
\hline \multirow{5}{*}{$\begin{array}{c}\text { C.I. } \\
\text { Vat Red } 1\end{array}$} & 0 & $3 / 4$ & 5 & 5 & $3 / 4$ & 5 & 5 & 5 \\
\hline & 5 & 5 & 4 & 5 & 4 & 5 & 5 & 5 \\
\hline & 7.5 & $4 / 5$ & 4 & 5 & 4 & 5 & 5 & 5 \\
\hline & 15 & $4 / 5$ & 5 & 5 & 5 & 5 & 5 & 5 \\
\hline & 20 & $3 / 4$ & 5 & 5 & 4 & 5 & 5 & 5 \\
\hline \multirow{5}{*}{$\begin{array}{c}\text { C.I. } \\
\text { Vat Green } 1\end{array}$} & 0 & 3 & 5 & 5 & 5 & 5 & 5 & 5 \\
\hline & 5 & $4 / 5$ & $3 / 4$ & 5 & 4 & 5 & 5 & 5 \\
\hline & 7.5 & 5 & $3 / 4$ & 5 & 4 & 5 & 5 & 5 \\
\hline & 15 & $4 / 5$ & 4 & 5 & 5 & 5 & 5 & 5 \\
\hline & 20 & $3 / 4$ & 3 & 5 & $4 / 5$ & 5 & 5 & 5 \\
\hline
\end{tabular}

viscose rayon with three vat dyes according to a different amount of reducing agent. We found that smaller particle size of leuco vat dyes have a greater specific surface area than large particles, and would be expected to react more rapidly unless over reduced by adding excessive reducing agent. Also, a sample with a larger proportion of small particles would be expected to reduce more rapidly than a sample with predominantly large particles. The color yield of the vat dyes on regular viscose rayon was dependent on the amount or concentration of the dyebath auxiliaries, especially reducing agent to convert leuco vat dye. For the wash fastness test, vat dyes exhibited good build-up on regular viscose rayon in terms of shade change and very little staining to the adjacent multifiber when reducing agent added concentration was between 5-7.5 g/l.

\section{Acknowledgements}

We are grateful to the support of this work by Graduate
Student Support Plan (GSSP) in the college of Textiles, North Carolina State University, USA.

\section{References}

1. J. R. Aspland, "Textile Dyeing and Coloration", pp.53-63, AATCC, Research, Triangle Park, 1997.

2. D. M. Nunn, "The Dyeing of Synthetic-Polymer and Acetate Fibres", pp.113-115, Dyers Company Pub., London, Triangle Park, NC, 1997.

3. C. S. Hughey, Text. Chem. Col., 12, 38 (1980).

4. H. G. Brittain, Pharm.Technol., 25, 38 (2001).

5. H. Musshoff, J. Soc. Dyer. Colour, 69, 119 (1953).

6. J. R. Aspland, Text. Chem. Col., 24, 27 (1992).

7. C. Senior, "Cellulosics Dyeing", pp.255-261, Society of Dyers and Colourists, Bradford, 1985.

8. J. J. Lee, W. S. Shim, I. S. Kim, and J. P. Kim, Fibers and Polymers, 6, 244 (2005). 